A N N A L E S Annales de Bretagne et des Pays de l'Ouest

\title{
Les miracles posthumes de saint Aubin d'Angers
}

\section{Élisabeth Carpentier et Georges Pon}

\section{(2) OpenEdition}

Journals

Édition électronique

URL : http://journals.openedition.org/abpo/3819

DOI : $10.4000 /$ abpo.3819

ISSN : 2108-6443

Éditeur

Presses universitaires de Rennes

Édition imprimée

Date de publication : 12 juillet 2018

Pagination : 37-62

ISBN : 978-2-7535-7604-9

ISSN : 0399-0826

Référence électronique

Élisabeth Carpentier et Georges Pon, «Les miracles posthumes de saint Aubin d'Angers », Annales de Bretagne et des Pays de l'Ouest [En ligne], 125-2 | 2018, mis en ligne le 12 juillet 2020, consulté le 06 janvier 2021. URL : http://journals.openedition.org/abpo/3819; DOI : https://doi.org/10.4000/abpo. 3819 


\title{
Les miracles posthumes de saint Aubin d'Angers
}

\author{
Élisabeth CARPENTIER \\ Professeur honoraire à l'université de Poitiers
}

Georges Pon

Maître de conférences honoraire à l'université de Poitiers

\begin{abstract}
L'histoire des origines de l'abbaye Saint-Aubin est assez obscure' ${ }^{1}$. Selon certains auteurs qui ne citent pas leurs sources ${ }^{2}$, Aubin aurait été enterré dans un caveau de l'église Saint-Pierre d'Angers. Quelques années plus tard, son corps, selon Fortunat lui-même (c. 53), a été transporté par saint Germain de Paris, par son successeur, et les autres évêques de la province dans une " nouvelle basilique " dédiée à saint Étienne ou à saint Germain avant de prendre le nom de saint Aubin ${ }^{3}$. Cette église aurait été construite sur l'ordre du roi Childebert (511-558), si on en croit une charte du 28 février 972 de l'évêque d'Angers Nefingus ${ }^{4}$, qui manifeste la prétention de Saint-Aubin d'être une abbaye royale disposant de privilèges liturgiques et notamment d'être le lieu de consécration des évêques d'Angers ${ }^{5}$. Retenons ici que Saint-Aubin fut, comme Saint-Hilaire de Poitiers ou SaintMartin de Tours et bien d'autres établissements religieux, une basilique
\end{abstract}

1. Selon François Chamard (La vie des saints personnages de l'Anjou, t. I, Paris, 1863, p. 217), la nouvelle église aurait été construite par le roi Childebert "à la place de l'ancienne chapelle de Notre-Dame-du-Verger, élevée par saint Hilaire de Poitiers ".

2. Dictionnaire d'histoire et de géographie ecclésiastiques, t. V, Paris, 1911, col. 254.

3. Vies des saints et des bienheureux, t. III, Paris, 1941, p. 14. Les reliques de saint Aubin auraient été placées dans une chapelle souterraine, une confessio, située au-dessous du grand autel (CHAMARD, François, La vie des saints personnages de l'Anjou [supra, n. 1], p. 218). C'était le 30 juin 556.

4. Cartulaire de Saint-Aubin, éd. Broussillon, Bertrand DE, t. I, Paris, 1903, n ${ }^{\circ}$ xx p. 35-36 : Sciant igitur successores nostri ecclesiam Beati Albini quae a sancto Germano, Parisiorum episcopo, voluntate et imperio Childeberti regis, ante portam Andecavensis urbis, versus orientem fundata est, quedam privilegia ex antiquitate pre ceteris Andecavensibus ecclesiis utpote regalem abbatiam obtinuisse.

5. Gullot, Olivier, Le comte d'Anjou et son entourage au XI ${ }^{e}$ siècle, t. I, Paris, 1972, p. $199-200$. 
suburbaine, d'abord desservie par des clercs ${ }^{6}$. Ils ont fait place aux moines. Dans l'acte de 972, l'évêque transfère les privilèges « détenus depuis longtemps par les chanoines de cette église aux frères qui servent maintenant aussi Dieu selon la règle en ce lieu ${ }^{7}$ ". Le comte Geoffroy Grisegonelle, en effet, dans les premières années de son gouvernement, entre 960/961 et le 19 juin 966, avait imposé une réforme marquée par l'arrivée de moines venus de Saint-Remi de Reims et la suppression de l'abbatiat laïque détenu par le comte et son frère Gui ${ }^{8}$.

Sous la protection et la " surveillance " des comtes ${ }^{9}$, Saint-Aubin devint aux XI ${ }^{\mathrm{e}}$ et $\mathrm{XII}^{\mathrm{e}}$ siècles une des plus importantes abbayes angevines avec Saint-Serge d'Angers et Saint-Florent de Saumur. Ses possessions étaient

6. Dans le premier miracle rapporté par Grégoire de Tours (I, 1a), la basilique est desservie par une communauté de " clercs " qui au "signal " d'une cloche " entonnent le chant de David ". Même chose dans le récit amplifié postérieurement (I, 2 a), même s'il est question plus haut du " monastère ".

7. ... privilegia quœe ex antiquo a canonicis ejusdem ecclesiae fuerunt obtenta, fratribus quoque nunc Deo ibidem regulariter servientibus nostre auctoritate cederemus atque firmaremus.

8. Annales de Saint-Aubin, dans : Recueil d'annales angevines ou vendômoises, éd. HALPHEN, Louis, Paris, 1908, p. 1 : DCCCCLXVI - De monasterio Sancti Albini canonici sunt ejecti et monachi sunt intromissi XIII kalendas Julii; Cartulaire de Saint-Aubin, [supra, n. 4], t. I, n 2, p. 4-7; OuRY, Guy Marie, "La reconstruction monastique dans la France de l'Ouest : l'abbé Gauzbert de Saint-Julien de Tours (v. 990-1007) ", Revue Mabillon, t. 54 (1964), p. 69-124; GuILlot, Le comte d'Anjou et son entourage [supra, n. 5], t. I, p. 138-151; JAROUSSEAU, Guy, "L'abbaye Saint-Aubin d'Angers, lieu d'une tradition royale de l'investiture de l'épiscopat ", dans Foi chrétienne et églises, dans La société politique de l'Occident du haut Moyen Âge (IVe-XIe siècle), textes réunis par HoAREAU-DoDINAU, Jacqueline et TEXIER, Pascal, Limoges, Pulim, 2004, p. 105-132, ici p. 106-107 : l'auteur analyse un acte ultérieur du 29 février 972 (éd. App. I, p. 120-126) de l'évêque Nefingus en faveur des moines de Saint-Aubin rappelant le caractère royal de l'abbaye Saint-Aubin; voir aussi Saint-Aubin d'Angers du VIe au XX siècle [Catalogue d'exposition], Angers, 1985.

9. Guillot, Le comte d'Anjou [supra, n. 5], p. 151 sqq.; Foulon, Jean-Hervé, Église et réforme au Moyen Âge. Papauté, milieux réformateurs et ecclésiologie dans les pays de la Loire au tournant des XI et XIf siècles, Bruxelles, 2008, p. 74; SENSÉBY, Chantal, "L'écrit monastique dans l'espace ligérien. Acteurs, productions et échanges ( $\mathrm{X}^{\mathrm{e}}$-XIII ${ }^{\mathrm{e}}$ siècles) ", Bulletin du Centre d'études médiévales d'Auxerre/Bucema, 19-1, 2015, [http://revues. org/13958]. SEnSÉBY, Chantal, "Écrire l'histoire à Saint-Aubin d'Angers au XII ${ }^{\mathrm{e}}$ siècle. Métamorphoses et fonctions des documents d'archives dans la production hagiographique ", dans : Écrire l'histoire au Moyen Âge. Contraintes génériques, contraintes documentaires, AnHeIm, Étienne, Chastang, Pierre, Mora-Lebrun, Francine et Rocheboute, Anne (dir.), Paris, Garnier, 2015, p. 37-58. SENSÉBY, Chantal, " Les scribes au travail à Saint-Aubin d'Angers (France de l'Ouest, $\mathrm{XI}^{\mathrm{e}}$ et $\mathrm{XII}^{\mathrm{e}}$ siècles) ", dans Le scribe d'archives dans l'Occident médiéval : formation, carrières, réseaux, colloque international organisé par BERTRAND, P., Hermand, X, Nieus, J.-F. et Renard, E., Namur, 2-4 mai 2012, sous presse; SEnsÉBy, Chantal, "Des moines et des écrits dans l'espace ligérien. Éléments pour une introduction ", dans L'écrit monastique. Acteurs, productions et échanges ( $X^{e}$-XIII siècle), Actes du colloque organisé par Chantal Senséby à Orléans au Centre international universitaire pour la recherche (hôtel Dupanloup), les 26 et 27 mars 2015, à paraître; L'écrit documentaire. Pratique et usage dans le Val de Loire (France de l'Ouest, XI -XI' siècle), 3 vol., 906 p., HDR soutenue en décembre 2012 à l'EPHE (présentation dans Revue Mabillon, n. s., 25, t. 86 [2014], p. 349-352). 
principalement situées dans les limites du comté d'Anjou ${ }^{10}$. L'abbatiale, remaniée et agrandie au $\mathrm{XII}^{\mathrm{e}}$ siècle, détruite au début du XIX ${ }^{\mathrm{e}}$, n'est connue que par quelques documents, plans, gravures, vestiges soigneusement analysés dans la thèse de Jacques Mallet ${ }^{11}$. On ne sait pas grand-chose de l'église antérieure au XI ${ }^{\mathrm{e}}$ siècle, mise à part l'existence d'une crypte de faibles dimensions, décrite par des érudits du XVII ${ }^{\mathrm{e}}$ siècle ${ }^{12}$. C'est dans cette crypte que reposait, semble-t-il, le corps de saint Aubin depuis le $\mathrm{VI}^{\mathrm{e}}$ siècle et c'est sur cette tombe que se sont produits la plupart des miracles décrits par les hagiographes. On en compte près d'une vingtaine entre la fin du $\mathrm{VI}^{\mathrm{e}}$ siècle et 1100 .

On peut les répartir en trois ensembles chronologiques distincts. Deux de ces miracles ont eu lieu peu de temps après la disparition de saint Aubin, puisqu'ils sont rapportés par Grégoire de Tours dans le Liber in gloria confessorum daté de 590 environ ${ }^{13}$. Le premier (I-1) ${ }^{14}$, écrit avec une grande sobriété, est la guérison d'un paralytique, transporté à Angers : alors qu'il passe la nuit devant un vitrail de l'abside où repose le corps de saint Aubin, il a une vision qui lui enjoint d'entrer dans l'église. Le second, très bref, rapporte la guérison le même jour d'une femme aveugle dans la bourgade de Craon. Ils ont été repris et amplifiés - surtout le second par un auteur anonyme à une époque inconnue mais qui est antérieure $\mathrm{au} \mathrm{X}^{\mathrm{e}}$ siècle, puisque ces deux " merveilles " ont été transcrites dans un manuscrit de l'Escorial remontant à cette époque $(\mathrm{I}, 2)^{15}$. Le remanieur du premier miracle a repris l'essentiel du récit $(B H L, 236 \mathrm{~b})$ : venue du paralytique à l'église, apparition ${ }^{16}$ d'un homme qui annonce l'arrivée dans la basilique des saints Martin et Aubin et ordonne à l'infirme de se rendre sur la tombe pour y être guéri. Il précise cependant que le miracle a eu lieu pour la Saint-Aubin d'été.

Dans le second cas, le miracle à distance qui renforce la " vertu " du saint, le remanieur avait toute liberté de broder sur la guérison à Craon de la femme aveugle. Il confirme qu'elle s'est accomplie le même jour que la guérison du paralytique, qu'elle est connue de tous les citoyens d'Angers.

10. Halphen, Louis, Le comté d'Anjou au XI siècle, Paris, 1903, p. 87-89.

11. MaLLET, Jacques, L'art roman de l'ancien Anjou, Paris, 1984, p. 38 sqq.

12. Ibid., p. 39. Remarquons cependant que Grégoire de Tours ne décrit pas nettement la crypte et situe le sépulcre de saint Aubin dans l'abside.

13. Voir en dernier lieu sur cette œuvre Heinzelmann, Martin, "Grégoire de Tours et l'hagiographie mérovingienne ", dans Gregorio Magno e l'agiografia fra IV e VII secolo, DEgL'InNocEnTI, A. et alii (dir.), Florence, 2007, p. 155-192, notamment p. 182-184.

14. Les miracles de saint Aubin ont été édités par KRUSCH, Bruno, Gregorii episcopi Turonensis Liber in gloria confessorum, 94, mgh, srm, I, 2, Hanovre, 1885, p. 358-359. Ils appartiennent à la troisième partie du texte après l' " entrée " consacrée au miracle opéré par les anges et les récits qui traitent des archi-confesseurs gaulois, Hilaire de Poitiers, Eusèbe de Verceil, Martin de Tours.

15. Manuscrit de l'Escorial, \& III, 26, x siècle, fol. 100-104, éd. KRUSCH, Bruno, mgh, aa, t. IV 2, Berlin, 1885, p. XII-XIV, sous le titre : Incipiunt miracula post obitum patrata.

16. Les visions, absentes de la Vita s. Albini, jouent un rôle important dans les Vitae gauloises de l'Antiquité tardive, notamment les Vitae Patrum de Grégoire de Tours. 
Sans citer Grégoire de Tours, il affirme que le miracle a eu lieu du temps de l'auteur (" de notre temps "). En rajeunissant le récit, on confère au miracle plus de force et de présence.

Le deuxième groupe (II) se réduit à un unique miracle, la guérison d'un moine bourguignon, venu en pèlerinage à Saint-Aubin d'Angers (BHL, 236c). Ce miracle a été ajouté sur les derniers folios d'un légendier du XIII ${ }^{\mathrm{e}}$ siècle $^{17}$ " par une main de la fin du XIV ou du début du XVe siècle ". Ce récit a été écrit par un moine de Saint-Aubin et rapporte des miracles survenus au temps de l'évêque Hubert (1006-1047) ${ }^{18}$, du comte Foulque Nerra, mort en 1040 et de sa seconde épouse Hildegarde ${ }^{19}$. L'histoire est confuse, verbeuse (c. 6) et redondante mais son auteur sait aussi parfois s'exprimer avec une prudence délicate lorsqu'il évoque en quelques mots la personnalité de Foulque Nerra : "...bien qu'il fût très dur envers ses ennemis, il était d'une grande affabilité pour ceux qui lui étaient attachés par l'amitié et la fidélité " ou quand il couvre l'évêque Hubert de flatteries peut-être excessives (c. 4).

Le récit nous est parvenu divisé en leçons, comme d'autres textes de ce manuscrit, destinés à un office monastique. Mais, comme l'a relevé l'éditeur, Joseph van der Straeten, " cet office [...] n'est pas structuré selon les usages liturgiques habituels ${ }^{20}$ ". Il manque les leçons tirées de l'Écriture et les leçons homélitiques. Les neuf leçons narratives, qui constituent l'essentiel de ce texte, sont suivies de trois leçons présentant une réflexion sur le miracle et une comparaison avec les miracles accomplis par Grégoire le Grand au temps de la grande peste ${ }^{21}$.

Le troisième groupe (III), comprenant un prologue et cinq miracles du $\mathrm{XI}^{\mathrm{e}}$ siècle, répartis en 16 chapitres, a été composé par un ou plusieurs moines de l'abbaye Saint-Aubin, après la mort d'Otbran, abbé de Saint-

17. Bibliothèque municipale d'Angers, ms 123 [115] provenant de Saint-Aubin. VAN DEN STRAeTEn, Les manuscrits hagiographiques d'Orléans, Tours et Angers, Bruxelles, 1982 (Subsidia hagiographica, 64), p. 213 sqq. pour la description du manuscrit, p. 280-283 pour l'édition.

18. Gulllot, Le comte d'Anjou et son entourage [supra, n. 5], t. II, p. 329.

19. La présence (c. 4) aux cérémonies de Saint-Aubin du "prince du pays " (Foulque Nerra) et de sa sage épouse - il s'agit de sa seconde épouse Hildegarde, car la première, tuée en l'an 1000 par son mari, était moins sage - est tout à fait possible compte tenu des liens qui unissaient le comte à l'évêque Hubert et à l'abbaye. En revanche, on comprend mal la mention de la "bienveillante mère " de Foulque Nerra, Adèle de Vermandois, qui avait disparu en 974 (BACHrach, Bernard S., Fulk Nerra, The Neo-roman Consul, a Political Biography of the Angevin Count, Berkeley/Los Angeles/Londres, 1993, p. 277).

20. On retrouve le même procédé dans un autre manuscrit provenant de Saint-Aubin (Bib. mun. d'Angers, 806 [722], fol. 25-26v [A1]) : légendier du XII ${ }^{\mathrm{e}}$ siècle utilisé pour le calibrage en 8 leçons d'un texte composé pour la fête de saint Maixent dans un lectionnaire de Saint-Aubin d'Angers achevé en 1287.

21. Des œuvres de Grégoire le Grand se trouvaient dans le riche catalogue du XII ${ }^{\mathrm{e}}$ siècle de la bibliothèque de Saint-Aubin (VEzIN, Jean, Les scriptoria d'Angers au XIe siècle, Paris, 1974 (Bibliothèque des hautes études, IV e section - Sciences historiques et philologiques, $322^{\mathrm{e}}$ fasc.), p. 216-218). La bibliothèque municipale d'Angers conserve le Liber pastoralis et les Homiliae de Grégoire le Grand (ms 191 [183]). 
Aubin de 1060 à $1081^{22}$, puisque l'un des miracles ${ }^{23}$ renvoie au temps où "l'abbé Otbran gouvernait l'abbaye " $(B H L, 236)$. Mais il rapporte aussi des événements qui se sont produits auparavant sous Gautier, abbé de SaintAubin (1035-1054) :

"Et bien que j'aie entendu les choses que j'écris du seigneur Gautier, alors doyen du monastère, et maintenant abbé (c'est lui qui m'a vivement incité à confier ce récit à la plume) et de nombreux autres qui furent présents à ce miracle, j'ai appris cependant avec plus de certitude tout cela de la bouche de Germond [le miraculé] et les ai mises par écrit pour répondre à sa prière répétée et ses supplications ${ }^{24}$."

Il faudrait donc admettre que l'auteur ait commencé sa carrière monastique avant 1035 et vivrait encore dans les années 1080 et suivantes, ce qui témoigne d'une longévité assez exceptionnelle ${ }^{25}$ mais il avoue lui-même dans le prologue qu'il n'a pas été témoin de tous les faits qu'il rapporte et qu'il les a connus " par le récit d'hommes fidèles auxquels je dois apporter foi en raison de leur grand âge et de leur vie sainte ". C'est le cas sans aucun doute du récit de la victoire des Guérandais sur les Normands (III-A, 12-14) qu'il est difficile de dater, puisque les Normands ont attaqué ou occupé les régions de la basse Loire du milieu du IX ${ }^{\mathrm{e}}$ siècle jusqu'en $937^{26}$. Notons cependant que le texte édité par les Bollandistes d'après un manuscrit de Saint-Nicolas de Belfort qui a, semble-t-il, disparu ${ }^{27}$ est connu également par un autre manuscrit conservé dans le fonds de la reine Christine à la Bibliothèque Vaticane, daté du XI ${ }^{\mathrm{e}}$ siècle par Albert Poncelet ${ }^{28}$. Il n'est donc pas impossible que ce recueil ait été composé à la fin de ce siècle. Ce qui pourrait confirmer cette datation, c'est une certaine qualité d'écriture et une richesse de vocabulaire assez surprenantes dans ce récit anonyme d'un moine de Saint-Aubin.

En eux-mêmes les miracles n'ont guère d'originalité : une majorité sont des miracles de guérison concernant deux cas de possession diabolique (III-A, 1-2), une victime du feu des ardents (I, 3), un paralytique (II, 4-11), un moine bourguignon atteint d'un mal mystérieux faussement diagnostiqué

22. Les Annales de Saint-Aubin datent la mort d'Otbran de 1081 (Recueil d'annales angevines et vendômoises, éd. HALPHEN [supra, n. 8], p. 5).

23. III-C, 15-16.

24. III-B, 11.

25. Prologue de III-C.

26. La chronique de Nantes, éd. MERLET, René, Paris, 1896 (Collection de textes pour servir à l'étude et à l'enseignement de l'histoire), passim. Voir TonNERRE, Noël Yves, Naissance de la Bretagne, Angers, Presses de l'université d'Angers, 1994, p. 269 sqq. La date de 919, retenue par certains historiens locaux n'a pas de fondement sérieux. Une dernière vague d'invasions normandes a menacé les rivages de l'Océan atlantique au début du $\mathrm{XI}^{\mathrm{e}}$ siècle (AdÉmar de Chabannes, Chronique, III, 53, trad. fr. par Chauvin, Yves et Pon, Georges, Paris, 2003, p. 266) mais a-t-elle touché la basse Loire?

27. Acta sanctorum, Martis I, p. 60-63 d'après un manuscrit de Saint-Nicolas de Belfort.

28. Bibliothèque vaticane, $\mathrm{n}^{\circ} 1025, \mathrm{~ms}^{\mathrm{du}} \mathrm{xl}^{\mathrm{e}}$ siècle, sans indication de provenance, qui a appartenu au XIII à l'abbaye de la Trinité de Vendôme, fol. 183-188, éd. partielle des passages inédits par PONCELET, Albert, Catalogus codicum hagiographicorum latinorum Bibliothecae Vaticanae, Bruxelles, 1909 (Subsidia hagiographica, 9), p. 403-404. 
comme une peste inguinale (II) ; un seul miracle de châtiment, la punition d'un adolescent privé de la parole (III-A, 1) pour avoir poussé des jurons. Ils nous renseignent cependant sur certains aspects de la vie quotidienne, notamment les différents modes de circulation et de transport utilisés à cette époque, le pèlerinage à pied de Germond pour Saint-Martin de Tours (III-B, 4), l'âne acheté par le même pour se rendre à Rome avec sa femme (III-B, 7) ; l'usage de béquilles par l'infirme (III-B, 6), de chevaux pour les déplacements de chevaliers (III-B, 5) ${ }^{29}$, d'animaux de bât pour le transport du blé de Thouars à Chemillé (III-C, 15). Relevons que le fils du chevalier du château de Chemillé est envoyé à Thouars avec des bêtes de somme lourdement chargées à l'aller et qui doivent rapporter du blé au retour. Cet adolescent ne se contente pas de diriger l'expédition mais participe à la tâche et c'est " en voulant relever le bât déséquilibré d'un âne ", qu'il " se fit très mal à la blessure qui lui avait été cruellement infligée récemment à la main ". L'éducation d'un jeune noble ne se limite pas à la pratique du combat.

Les récits du moine de Saint-Aubin nous renseignent aussi sur les "solennités " qui marquaient les vigiles de l'anniversaire du saint patron : " hymnes mélodieux, cantiques spirituels, psaumes au lever du jour ${ }^{30}$ ». Ces cérémonies réunissaient non seulement l'abbé, les dignitaires et les moines de Saint-Aubin mais d'autres " abbés accompagnés de leurs moines ", des clercs, des laïcs ainsi qu'une foule appréciable de moines. Les détails fournis par l'hagiographe ont même permis à Jacques Mallet de donner une image plus précise du chœur de l'abbatiale et du tombeau du saint.

L'abbatiale n'est connue, on l'a dit, que par quelques documents ${ }^{31}$. On ne sait pas grand-chose de l'église ancienne, sauf l'existence d'une crypte de faible dimension ${ }^{32}$. Après l'incendie de $1032^{33}$, sans sacrifier la crypte qui

29. Notons que le pauvre Germond, secouru par des cavaliers, transporté au château de Baugé à cheval, finit son voyage jusqu'à Angers sur un âne.

30. CHAMARD, La vie des saints [supra, n. 1] cite aussi l'invocation qui servait de préface, le jour de sa fête, d'après un manuscrit du $\mathrm{X}^{\mathrm{e}}$ siècle conservé à la bibliothèque municipale d'Angers : " Délivrez-nous Seigneur des chaînes qui captivent notre âme, ô Dieu éternel, nous vous en supplions par notre Seigneur Jésus-Christ qui a donné à notre Église en la personne du bienheureux pontife Aubin, un modèle aussi parfait qu'admirable. L'Église catholique, répandue sur tous les points du globe, se glorifie et se réjouit des œuvres excellentes et de la vie si digne de louanges de ce serviteur fidèle. Sa mort glorieuse et son entrée triomphante dans les cieux font aujourd'hui le sujet des harmonies divines des neuf chœurs des Esprits bienheureux. Permettez-nous de nous unir à tant de concerts et d'élever nos cœurs jusqu'à vous, notre Dieu et notre récompense éternelle! Amen. "

31. En 1070, les Annales de Saint-Aubin mentionnent l'élévation des reliques des saints Aubin et Clair (HALPHEN, Louis, Recueil des Annales angevines et vendômoises [supra, n. 8], p. 5). Plus tard, en 1128 (BHL, 237), les reliques sont transférées dans une nouvelle châsse : MXXVIII. Translatio sancti Albini, kalendis martis in novam capsam (op. cit., p. 8) ; MALlET, Jacques, L'art roman de l'ancien Anjou [supra, n. 11], p. 39. Voir infra, nº V.

32. MALLET, Ibid., p. 39. Remarquons cependant que Grégoire de Tours ne mentionne pas nettement l'existence d'une crypte puisqu'il semble situer le sépulcre de saint Aubin dans l'abside : " un paralytique, dont tous les membres étaient atteints, soulevé de son brancard, était assis devant la vitre de l'abside où les saints membres du saint étaient enfermés ". Est-ce une allusion à une ouverture éclairant la crypte à l'est de l'église?

33. De suburbio cum toto monasterio Sancti Albini [pars] maxima deperiit (HALPHEN, Le comté d'Anjou [supra, n. 10], p. 96-97 et MALLET, L'art roman de l'ancien Anjou [supra, 
contenait le corps de saint Aubin, on a reconstruit vers l'ouest, au milieu du $\mathrm{XI}^{\mathrm{e}}$ siècle, dans un style peu original un édifice plus vaste pouvant accueillir une importante communauté qui comptait plus d'une centaine de moines en $1082^{34}$ : nef charpentée à bas-côtés, croisée carrée et chœur sans déambulatoire ${ }^{35}$ surmontant la crypte où reposait le corps de saint Aubin depuis le $\mathrm{VI}^{\mathrm{e}}$ siècle. Mais après deux translations en 1070 et en 1128, il semble bien que le tombeau était vide ${ }^{36}$. Les récits de miracles ne confirment qu'imparfaitement cette conclusion ${ }^{37}$. "Germond, bien qu'avec peine, était entré dès le matin dans le sanctuaire (presbyterium) [...] ; il s'était prosterné entre les deux autels. "Après des prières ferventes, "se levant, il se dirigea jusqu'aux portes (januas) devant l'autel dominical ». C'est là qu'il fut guéri : " il se dressa sur ses deux pieds, et la démarche droite, il s'avança devant tous glorifiant l'auteur de sa guérison " (III-B, 9) ${ }^{38}$. Il n'est dit nulle part que Germond, encombré de ses béquilles, est descendu dans la crypte. Il n'est pas question de la présence d'un mausolée ou d'une châsse. L'infirme s'était " prosterné entre les deux autels ". Il s'agit-il de deux autels situés dans le sanctuaire : l'autel dominical où a lieu la guérison ${ }^{39}$ et un autel plus à l'est consacré à saint Aubin. C'est l'interprétation, semble-t-il, de Jacques Mallet. C'est aussi la nôtre. Mais dans ce cas on comprend mal l'affirmation selon laquelle il était entré dès le matin dans le presbyterium qui désigne manifestement le sanctuaire. Rien non plus ne prouve la présence d'une crypte dans le miracle que rapporte le lectionnaire d'Angers. Le timide moine bourguignon est invité par les autorités à venir dans le chœur (choro) et c'est là que, s'avançant jusqu'à la tombe (tumulum) du saint, il ressent les signes de sa guérison (II, 8). Un autre miracle du troisième groupe est heureusement moins ambigu. C'est celui du jeune noble de Chemillé devenu muet : les moines l'enferment dans le sacrarium pour qu'il y passe la nuit. Ce " lieu saint " semble ici désigner la crypte - c'est du moins ainsi que l'interprète Jacques Mallet : il contient le sépulcre (mausoleum) où repose le corps très saint de saint Aubin qui apparaît au jeune muet. C'est par la vitre disposée " devant le mausolée " (III, 16), que le saint échappe à la vue du jeune homme, ce qui s'accorde assez bien à la description donnée par Grégoire de Tours dans le premier de nos miracles : la crypte a une fenêtre ouverte sur l'est qui permet la sortie de saint Aubin.

n. 11], p. 40). Des textes mentionnent un autre incendie à Angers en 1036 qui détruisit la cathédrale et « la plus grande partie du faubourg avec le monastère tout entier de SaintAubin, La chronique de Saint-Maixent, éd./trad. VERDON, Jean, Paris, 1979 (Les classiques de l'histoire de France au Moyen Âge), p. 119.

34. Cent-cinq moines étaient présents pour l'élection de l'abbé Girard en 1082 (Cartulaire de Saint-Aubin [supra, n. 4], $\mathrm{n}^{\circ} \mathrm{XXXI}$, p. 53-55) contre 57 seulement pour l'élection de Gautier en décembre 1038 (Ibid., $\mathrm{n}^{\circ}$ XXVII, p. 45-47).

35. MALLET, L'art roman de l'ancien Anjou [supra, n. 11], planches XXV et XXVI.

36. Supra, n. 31.

37. MALLET, Ibid., p. 40.

38. MALLET, Ibidem.

39. DolBEAU, François, " Pierre, moine de Saint-Serge, hagiographe angevin au $\mathrm{XII}^{\mathrm{e}}$ siècle et son milieu ", dans DolBEAU, François, Sanctorum societas. Récits latins de sainteté (III XII siècles), t. II, Bruxelles, 2005, p. 815-825. 
Cette œuvre est à replacer dans l'histoire littéraire de l'Anjou avant 1100 et l'activité du scriptorium de Saint-Aubin au $\mathrm{XI}^{\mathrm{e}}$ siècle, qui ont été fort bien éclairées l'une et l'autre par les travaux de Jean Vezin et de JeanHervé Foulon ${ }^{40}$. Ils ont montré l'existence d'une école cathédrale à Angers dès le début du XI ${ }^{\mathrm{e}}$ siècle, animée par des disciples de Fulbert de Chartres, notamment le célèbre Bernard de Chartres, qui a fait le voyage à Conques pour réunir un important dossier des miracles de sainte Foy ${ }^{41}$ et plus tard Renaud, grammaticus et magister scholarum, lui-même auteur d'un recueil de miracles du patron de Saint-Florent de Saumur. C'est dire que la production hagiographique était bien connue à Angers depuis le $\mathrm{X}^{\mathrm{e}}$ siècle $^{42}$. Il n'y a pas beaucoup de traces d'une école à Saint-Aubin, sauf la présence d'un moine du nom d'étienne, souvent mentionné parmi les frères présents dans des actes divers et qualifié d'ancien magister scolarum dans une notice de $1092^{43}$. Peut-être cet Étienne est-il l'auteur d'un ou de plusieurs des miracles du troisième groupe de miracles édités dans les Acta sanctorum. Si le monastère de Saint-Aubin n'est pas un grand centre culturel ${ }^{44}$ comme la cathédrale au temps de Bérenger, de Renaud, de Marbode ${ }^{45}$, ou même l'abbaye de Bourgueil au temps de Baudri, c'est un foyer de production hagiographique qui n'est pas négligeable. Thierry, abbé de SaintAubin de 1046 à 1060, avait déjà composé un recueil de miracles de saint Aubin qui a malheureusement disparu ${ }^{46}$. Peut-être notre hagiographe a-t-il souhaité poursuivre son œuvre après la translation des reliques de saint Aubin et de saint Clair, mentionnée en 1070 par les annales de l'abbaye ${ }^{47}$.

40. VezIN, Jean, Les scriptoria d'Angers au XI siècle [supra, n. 21]; Id, " La vie intellectuelle en Anjou pendant le $\mathrm{xl}^{\mathrm{e}}$ siècle », dans La littérature angevine médiévale. Actes du colloque du samedi 22 mars 1980, Angers, 1981, p. 13-23 et GullLot, Olivier, À propos de la qualité littéraire de certaines chartes angevines au XI siècle, ibidem, p. 25-39. Voir aussi Foulon, Église et réforme au Moyen Âge [supra, n. 9], p. 136 sqq.

41. Robertini, Luca, Liber miraculorum sancte Fidis, Spolète, Centro italiano di studi sull'alto medioevo, 1994. Voir BonNASSIE, Pierre et GouRnAY, Frédéric DE, "Sur la datation du Livre des miracles de sainte Foy de Conques ", Annales du Midi, t. 107 (1995), p. 457-473.

42. Vie de saint Maurille composée vers 905 par un diacre de l'église d'Angers (BHL, $5731)$; récit des miracles de la translation des reliques du saint évêque avant 987 ( $B H L$, 5733), Vezin, la vie intellectuelle en Anjou [supra, n. 40], p. 13.

43. Cartulaire de l'abbaye de Saint-Aubin d'Angers, éd. BRoussillon, Bertrand DE, $\mathrm{n}^{\circ} \mathrm{DCCXXX}$ VII, t. II, Paris, 1903, p. 224 : Quod Sancti Albini monachi audientes, veris testimoniis falsum esse ostenderunt, Stephanus enim, Sancti Albini monachus, qui tunc magister scolarum fuerat....

44. Notons cependant que le cloître de Saint-Aubin témoigne que ce monastère était un lieu de réflexion liturgique et exégétique, comme l'a montré éric Palazzo (Mittelalterliche Kreuzgang Architektur Funktion und Programm, KLEIN, Peter K., éd., Regensburg, 2004, p. 220-240).

45. Renaud a composé une Vie de saint Florent (bhl, 3047) et Marbode écrit ou réécrit plusieurs vies de saints en vers ou en prose (VEzIN, La vie intellectuelle en Anjou [supra, n. 40], p. 19).

46. Vezin, Les scriptoria d'Angers au XI siècle [supra, n. 21], p. 14. Voir aussi DuboIS, Jacques, "Une œuvre littéraire à Saint-Aubin, la vie de saint Girard au XII ${ }^{\mathrm{e}}$ siècle ", $L a$ littérature angevine médiévale. Actes du colloque du 22 mars 1980, Angers, 1981 p. 51-62.

47. Recueil des annales angevines et vendômoises, éd. HALPHEN [supra, n. 8], p. 5. 
C'est aussi à la fin du siècle que le scriptorium de Saint-Aubin produisit le remarquable codex enluminé de la fin $\mathrm{du} \mathrm{XI}^{\mathrm{e}}$ contenant des images de la vie de saint Aubin ${ }^{48}$.

Il est certain que notre hagiographe n'a pas la culture de son contemporain Marbode. La seule réminiscence antique que contienne le recueil - " Le jour qui est dédié à Mercure par les Anciens qui étaient dans l'erreur ${ }^{49}$ " - ne donne pas une très bonne idée de ses lectures profanes. Mais il maîtrise les codes de l'écriture hagiographique. Le prologue multiplie les lieux communs et les protestations d'insuffisance. Il ne manque pas d'évoquer sa " pauvre petite personne, ignorante de toute espèce de philosophie " et se plaint de sa " plume rustique ${ }^{50}$ ". En bon moine, il se garde d'attribuer à saint Aubin lui-même l'action miraculeuse qui n'appartient qu'à Dieu ${ }^{51}$, même s'il entretient une certaine ambiguïté en citant les voix de la foule saluant les signes de la guérison ${ }^{52}$. Celle-ci est saluée par la liesse populaire et le Te Deum laudamus ${ }^{53}$. Il recourt à toutes sortes d'artifices tels que le rêve de Germond à Lucques où il lui semble apercevoir un " homme d'une grande autorité " lui ordonnant de quitter la ville pour retourner à Angers.

Ces récits de miracles n'ont pas les dimensions des grandes collections médiévales telles que celle à laquelle a participé un autre angevin, Bernard de Chartres. C'est cependant une utile contribution au culte de saint Aubin, illustré par Fortunat et Grégoire de Tours à la fin du VI ${ }^{\mathrm{e}}$ siècle, que de nombreux manuscrits ont répandu largement en Europe. "Tous les martyrologes anciens et modernes font mention de lui et son nom se trouve inscrit dans les plus anciennes litanies des saints qui aient été publiés jusqu'ici ${ }^{54}$." Ses reliques étaient vénérées à l'abbaye de Saint-Riquier au milieu de beaucoup d'autres ${ }^{55}$. De nombreuses églises portaient son nom, dont près d'une trentaine en Anjou ${ }^{56}$. Ce qui montre aussi la vitalité de son culte à la fin du

48. BnF, nouv. acq. lat., 1390. Il s'agit de 14 peintures qui sont l'œuvre d'un artiste actif à Angers vers 1100, qui a également participé à la décoration de trois autres manuscrits angevins : la Bible de Saint-Aubin en deux volumes (bibliothèque municipaled'Angers, ms 3-4) et un psautier glosé (bibliothèque municipale d'Amiens, fonds Lescalopier, ms 2) et que J. Porcher a suggéré d'identifier avec un certain Foulque, auquel l'abbé de SaintAubin, Gérard (1082-1108), avait commandé l'exécution des peintures murales et des vitraux de l'abbaye (notice descriptive du site de la BnF, avec importante bibliographie).

49. III-B, 15.

50. Il revient sur ses propres faiblesses lors de sa discussion avec Germond à la fin du chapitreII (III-B 11).

51. "... nuit et jour, il multipliait les prières au saint confesseur, afin qu'il intervînt pour lui auprès du Juge miséricordieux " (III-B, 11).

52. " À la suite de ce signe, vous le verrez bientôt guéri par la puissance à l'œuvre du saint " (III-B, 9).

53. III-B, 10.

54. ChAMARD, La vie des saints personnages de l'Anjou, [supra, n. 1], p. 204.

55. Lот Ferdinand, Chronique de l'abbaye Saint-Riquier, Paris, 1894 (Collection de textes pour servir à l'étude et à l'enseignement de l'histoire), p. 65.

56. ChAMARD, Ibid., p. 204. Voir aussi MATZ, Jean-Michel, " Le calendrier et le culte des saints : Saint-Aubin d'Angers (XII ${ }^{\mathrm{e}}$-début XVII ${ }^{\mathrm{e}}$ siècle "), Revue Mabillon, n. s., 768 (1996), p. 127-155, qui montre l'importance du culte du saint dans le calendrier du monastère. Ce 
$\mathrm{XI}^{\mathrm{e}}$ siècle ou au début du siècle suivant, ce sont les fragments mutilés aux deux extrémités d'une vie métrique de saint Aubin transcrite sur le f. Aiv du manuscrit de la bibliothèque municipale d'Angers, 299 (290). Il s'agit d'un poème qui versifie en hexamètres léonins les chapitres 14-17 du texte en prose de Fortunat ${ }^{57}$. Ces fragments ont été édités par François Dolbeau ${ }^{58}$.

\section{Les miracles}

\section{Miracles anciens : guérison du paralytique et de la femme aveugle}

Deux miracles rapportés par Grégoire de Tours (573-598) ${ }^{59}$

a. Le confesseur Aubin dont le prêtre Fortunat a récemment écrit la vie obtient aussi lui-même en raison de son mérite de montrer des miracles sur son tombeau. Voici que le jour de sa solennité, un paralytique, dont tous les membres étaient atteints d'infirmité, sorti de son chariot, se tenait devant la vitre de l'abside ${ }^{60}$ où les saints membres étaient enfermés. S'étant assoupi, il vit un homme qui venait vers lui en disant : "Jusqu'à quand vas-tu dormir, est-ce que tu ne désires pas être guéri? " Et lui de répondre : "Fasse le ciel que je mérite d'être guéri! " Et l'homme lui dit : "Quand tu entendras sonner la cloche pour les offices de la troisième heure, lève-toi aussitôt et entre dans la basilique vers laquelle tu es venu. Ce qui va se produire en effet, c'est qu'à cette heure même saint Martin avec son condisciple Aubin entre dans la basilique et que la prière faite, il doit aller à Tours pour sa solennité. Et si tu es là à ce moment-là, tu seras guéri. " Alors, l'infirme, sans s'attarder, dès que la cloche sonne, se rend au tombeau. Et comme les clercs commençaient à entonner le cantique de louange de David, une odeur suave se répand dans la basilique du saint et là, droit sur ses pieds, il se dresse guéri. Que cela a été vu non pas par un petit nombre de gens mais par une très nombreuse assistance, le pays qui l'a nourri en est le témoin (voir infra $2 \mathrm{a}$ ).

b. À noter aussi que dans la bourgade (vicus) de Craon, une femme aveugle de naissance retrouva la lumière ce même jour en invoquant le nom du saint (voir infra $2 b$ ).

calendrier mentionne quatre fêtes : le $1^{\mathrm{er}}$ mars pour la depositio $s$. Albini et la translation des reliques de 1128, le 30 juin pour la translatio $s$. Albini de 556 " aussi appelée translation d'été ", le 7 juillet pour l'octave, le 25 octobre pour une autre translation de saint Aubin du 30 octobre 1070 (tableau, p. 132 et p. 134-135).

57. Dolbeau, Pierre, moine de Saint-Serge, [supra, n. 39], p. 819.

58. Ibid., p. 821-822. Nous en donnons la traduction ci-dessous (IV).

59. Gregorii episcopi Turonensis Liber in gloria confessorum, 94, éd. KRUSCH, Bruno, mgh, srm, I, 2, Hanovre, 1885, p. 358-359.

60. Comprenons que le paralytique se trouvait alors à l'extérieur de l'église. 


\section{Versions postérieures ${ }^{61}$}

\section{a. Guérison du paralytique}

Le saint confesseur Aubin, éminent évêque d'Angers, dont Fortunat s'est attaché à écrire les nobles actes d'une plume élégante, obtint par ses très grands mérites de montrer des miracles nombreux pour fortifier la foi des populations venues sur son tombeau. Le jour donc de sa fête qui est célébrée en été ${ }^{2}$, de grandes troupes de fidèles ont fréquenté le sanctuaire. Beaucoup aussi qui souffraient de diverses maladies et qui avaient entendu parler de la réputation de ses pouvoirs thaumaturgiques (virtutes) étaient venus pour obtenir la guérison. Parmi eux, un paralytique qui depuis longtemps languissait couché sur son lit, ayant perdu l'usage de ses membres, arriva porté sur un véhicule : il passa toute la nuit privé de sommeil, cherchant à obtenir la compassion (pietatem) du saint et qu'il le libérât par ses saints mérites de cette triste maladie. À cet homme qui gisait après les vigiles de la nuit, dehors, sous l'ouverture qui s'élevait au-dessus du tombeau et qui s'abandonnait au sommeil à la fin de la nuit, voici qu'un homme debout, au visage et au vêtement brillant apparaît qui lui dit : " Malheureux, pourquoi sommeilles-tu si longtemps? Est-il admissible que tu négliges le soin de ta vie? Persévère dans la prière et tu ne seras pas frustré de la récompense du salut. En effet, qui demande reçoit et qui cherche trouve, la porte s'ouvrira à celui qui frappe ${ }^{63}$. " Le malade lui répondit : "Fasse le ciel, honorable père, que je mérite de recouvrer la santé. " Mais lui ajouta : " Demande qu'on t'aide à être transporté dans le monastère et dès que le signal retentira, assiste à l'heure de matines en personne, prie Dieu avec confiance et tu seras guéri de l'infirmité qui te retient. À l'heure dite, voici que se présentent les glorieux prêtres du Christ, à savoir saint Aubin et le seigneur Martin, archevêque de Tours, pour entrer dans cette basilique : dans ce lieu, après la bénédiction, ils doivent venir à la solennité à la fois de la translation [de saint Aubin] et de l'ordination (ordinationis) dudit saint Martin de Tours : Toi donc, contente-toi de croire et si tu es présent à leur arrivée, tu seras sauvé. " Sorti faible de son engourdissement, sans retard il se hâta de se faire transporter à la tombe dans laquelle sont enfermés les membres sacrés. Ensuite, tandis qu'à la troisième heure les clercs chantaient les laudes de Dieu, la suavité d'une odeur remarquable, surpassant tous les aromates, se répandit dans tout le peuple qui se trouvait dans l'église. Rempli de cette douceur, le malade se sentit guéri et, comme s'il n'avait été frappé d'aucune infirmité, cet homme qui peu auparavant avait été transporté au sépulcre du saint confesseur, marchant sur ses pieds, se joignit à tout le peuple pour rendre des louanges au saint évêque Aubin. Ce ne sont pas quelques personnes mais un grand nombre de gens qui virent cela, tout l'Anjou en témoigne.

61. Manuscrit de l'Escorial, \& III, 26, x siècle, fol. 100-104, éd. KRUSCH, Bruno, mgh, aa, t. IV, Berlin, 1885, p. XIII-XIV, sous le titre : Incipiunt miracula post obitum patrata.

62. Il s'agit du 30 juin.

63. Mt 7, 8 et Lc 11, 10 : "Car quiconque demande reçoit, celui qui cherche trouve. " 
b. Guérison de la femme aveugle (op. cit., p. XIV)

En vérité ce n'est pas seulement le lieu où sont conservées les reliques du corps sacré de saint Aubin qui est illustré par des miracles répétés, mais aussi partout où son nom aura été évoqué avec une foi droite, le Christ œuvrant pour les mérites du confesseur afin que les fidèles obtiennent ce qu'ils demandent, afin que soit accomplie la phrase de vérité qui dit : " Mon Père est toujours à l'œuvre et moi aussi je suis à l'œuvre ${ }^{64}$. " Et de nouveau : "Les œuvres que je fais, que ceux qui croient en moi les accomplissent eux-mêmes ${ }^{65}$. " De fait il se trouva à Craon une femme que la nature, avec la permission de Dieu, avait fait naître aveugle dans cette vie. Apprenant de nombreux côtés que par la vertu du saint pontife les lépreux étaient purifiés, les paralytiques guéris, que les aveugles avaient retrouvé la vue et que de très nombreux malades désespérant de la vie avaient été pour ainsi dire arrachés à l'étreinte de la mort et rendus à la vie, cette femme invoquait avec foi, nuit et jour, saint Aubin du fond du cœur, pour qu'il apporte à son malheur l'aide accoutumée et lui permette par son intercession de voir la lumière du ciel que la nature lui avait refusée. Et elle ne cessa pas de le harceler avec audace de ses prières jusqu'à ce qu'elle obtînt du saint confesseur ce qu'elle demandait. Le même jour en effet où le paralytique dont nous avons parlé plus haut fut guéri dans le monastère, cette femme reçut la lumière dans la bourgade susdite, par la puissance de Notre Seigneur Jésus-Christ, Dieu qui vit et règne pour les siècles des siècles. Amen. Il me semble qu'il faut transcrire ce très célèbre miracle qui a été manifestement accompli de notre temps. Et j'estime qu'il faut surtout le faire connaître aux fidèles futurs par l'écrit, parce que je sais qu'il a été parfaitement vu et connu par les fidèles dans le présent. Aussi ce que je raconterai, je l'aurai appris par le récit de ceux dont je n'ai pas pris grand soin de citer les noms parce que ce sont tous des habitants d'Angers. 


\title{
Autre miracle du $X I^{e}$ siècle : guérison miraculeuse d'un moine [bourguignon] par Dieu, faite par l'intercession de saint Aubin 66
}

\author{
Leçon 1
}

Au temps où plus que d'habitude par suite d'une forte famine une calamité immense et générale touchait diverses provinces de la Gaule ${ }^{67}$, un moine originaire de Bourgogne ${ }^{68}$, qui souffrait chaque jour depuis longtemps d'une grave infirmité, averti par la charité de certains de ses amis ainsi que par la nécessité, gagna la cité d'Angers dans le faubourg ${ }^{69} \mathrm{de}$ laquelle se trouve le monastère qui conserve le corps très sacré du très saint confesseur Aubin, évêque de cette cité.

\section{Leçon 2}

Par bonheur il advint qu'au temps où ce frère arrivait à Angers, les citoyens du pays, selon une habitude respectant la tradition, célébraient la solennité de leur saint patron. Il vint en effet la veille des calendes de mars $^{70}$, au premier jour desquelles l'humble et pieuse dévotion de nombreux fidèles attend le jour de la fête dudit père. Ils étaient nombreux, venus de diverses régions, rassemblés dans l'attente d'une si grande célébration : abbés vénérables qui présentaient de façon remarquable le saint habit religieux suivant le rang, l'ordre et l'apparence.

\section{Leçon 3.}

Avec eux il y avait aussi la foule éclatante des moines qui servent virilement le Christ roi : ils dépassaient, je pense, la centaine ${ }^{71}$. était présent également l'évêque de cette cité, appelé Hubert ${ }^{72}$, homme d'une noblesse et d'une honnêteté parfaites, et, ce qui est encore mieux, doté du don d'une bienveillante spiritualité et de charité : il attendait avec joie la solennité de

66. Voir Introduction.

67. S'agit-il de la " grande calamité " mentionnée en 1028 par La Chronique de SaintMaixent, éd./trad. VERDON [supra, n. 33], p. 112-113? Une autre famine ravagea toute la Gaule en 1042 (op. cit., p. 121) mais elle est postérieure à la mort de Foulque Nerra.

68. Il existait au tournant $\mathrm{du} \mathrm{x}^{\mathrm{e}}$ et $\mathrm{du} \mathrm{xl}^{\mathrm{e}}$ siècle des liens entre Cluny et les abbayes ligériennes (OuRY, Guy, "La reconstruction monastique dans l'Ouest... " [supra, n. 8], p. 69-124). Les moines de Saint-Aubin possédaient même un manuscrit de la vie de saint Maïeul (Foulon, Église et réforme au Moyen Âge [supra, n. 9], p. 76). Mais ces liens semblent avoir disparu après l'an Mil (op. cit., p. 76-78). N'oublions pas cependant que Geoffroy Martel avait épousé la veuve de Guillaume le Grand en 1032, Agnès de Bourgogne.

69. L'abbaye Saint-Aubin était située en dehors des remparts antiques.

70. $1^{\mathrm{er}}$ mars, jour de la principale fête de saint Aubin.

71. Sur le nombre des moines à Saint-Aubin en 1038 et 1082, voir supra, n. 34 Sans doute avaient-ils été rejoints par des moines venus d'autres abbayes angevines.

72. Le portrait de Hubert, évêque d'Angers de 1006 à 1047, est trop flatteur. Olivier Guillot a bien montré que ce fils du vicomte de Vendôme, porté à l'épiscopat par le comte Foulque Nerra, a " fait plus figure de seigneur... que de grand prélat ". Mais après une politique fluctuante il a fini par se réconcilier avec le comte, si bien que pour un moine de Saint-Aubin de la première moitié du XI ${ }^{\mathrm{e}}$ siècle qui n'était pas influencé par une ecclésiologie réformatrice, il pouvait apparaître comme un excellent pontife (voir GulLLot, Le comte d'Anjou et son entourage [supra, n. 5], t. II, p. 224-249; voir aussi Foulon, Église et réforme au Moyen Âge [supra, n. 9], p. 56-63). 
son très saint prédécesseur; suivaient le clergé et le peuple unis à lui par une affection fraternelle et une filiation spirituelle.

\section{Leçon 4}

Le prince du pays était aussi présent avec sa très bienveillante mère et sa très sage épouse ${ }^{73}$ : bien qu'il fût très dur envers ses ennemis, il était d'une grande affabilité pour ceux qui lui étaient attachés par l'amitié et la fidélité. Quant à ce frère qui, comme on l'a dit, s'était rendu dans le susdit monastère, certains prétendaient et ses rivaux affirmaient qu'il était quantité négligeable ${ }^{74}$. Mais comme le voulaient ses amis, il semblait avoir quelque poids auprès de certaines personnes. Mais, quoi qu'il en soit, il fut accueilli alors par les susdits anciens de l'un et l'autre ordre et condition, avec un respect et des honneurs qui allaient au-delà de ce qui était convenable à son égard, et traité avec une charité évangélique et une humanité bienveillante.

\section{Leçon 5}

Après avoir constaté qu'il recevait ainsi de si grandes marques de respect, surpris, commençant à revenir au plus profond de sa conscience - cette conscience que personne ne peut fuir -, il reconnut que ce qui lui arrivait dépassait sans aucune comparaison son mérite, son pouvoir et son savoir. Mais en même temps il se rappelle que peu de temps auparavant il avait entendu dire que la divine miséricorde n'accorde pas ses bienfaits pour des mérites antérieurs, mais qu'elle rappelle qu'il faut corriger les négligences et invite à faire des choses utiles comme par un don gratuit.

\section{Leçon 6}

L'abbé du susdit monastère du très saint évêque Aubin, pourvu de sage simplicité et de simple sagesse, et les autres anciens qui étaient là priaient avec plus d'insistance ledit frère infirme de rester avec eux dans le chœur (choro) et de s'installer à la première place après les abbés. Mais ce moine qui à son habitude redoutait la témérité et craignait la honte n'osait pas s'avancer, parce qu'il pensait que dans la solennité des vigiles il ne pouvait pas se joindre à la sainte communauté à cause de son mal qui, aux heures de la nuit, pesait sur lui encore plus durement que d'habitude.

\section{Leçon 7}

Paralysé par la crainte et la honte, il redoutait, s’il désobéissait ouvertement aux anciens, de passer pour un ingrat aux yeux de tous. Que dire de plus? Ne pouvant trouver d'autre issue que d'obéir à l'ordre des anciens, paralysé et plein de zèle [à la fois], il avança jusqu'à la tombe du très saint pontife, il le supplie et le conjure de pouvoir accéder miséricordieusement au trône du divin pardon et dans sa sainte solennité il lui demande la faveur d'une largesse, à savoir que tous ceux qui célèbrent avec la plus grande dévotion la fête très sacrée de saint Aubin méritent auprès du Seigneur

73. Voir supra, n. 19.

74. Dans le texte latin, la construction ut erat est surprenante. 
à la fois le soutien pour la vie temporelle et la récompense de l'éternelle béatitude; [il demande aussi] de pouvoir acquérir pour lui-même dès maintenant le remède de l'infirmité où il se trouve à cause du dommage enduré, afin de pouvoir avec ses frères participer à la solennité des saintes vigiles et célébrer pleinement cette très illustre fête.

\section{Leçon 8}

Voici donc que ce frère infirme, aidé et guéri par les mérites et les prières du très saint évêque, disait en l'attestant par un serment conforme aux usages qu'après avoir commencé à se répandre en prières devant le saint autel, il sentit immédiatement qu'il allait beaucoup mieux, au point qu'il lui sembla pouvoir sans peine accomplir ce qu'il craignait d'entreprendre auparavant. Aussi, confiant dans la miséricorde de Dieu et les mérites de saint Aubin, soulagé et joyeux, il se sentit digne de se joindre toute la nuit aux anciens et aux frères qui récitaient les louanges d'un si grand patron.

\section{Leçon 9}

Et non seulement il sentit alors que la miséricorde de Dieu lui était venue en aide par les mérites du très saint Aubin mais après qu'il eut commencé à proclamer son mérite et à en faire mémoire quotidienne, il sentit et fut persuadé qu'il avait été très soulagé de la maladie qui le retenait, avec l'aide du Christ qui garantit à saint Aubin de fleurir de vertus et de se réjouir avec tous les saints dans le royaume des cieux. Qu'à l'assemblée des saints il nous permette de nous associer, Lui qui vit et règne dans tous les siècles des siècles. Amen.

\section{Leçon 10}

Pour le reste, très chers frères, ce moine infirme ne souffrit pas qu'on gardât le silence sur ce qui lui était advenu par les mérites du pieux père Aubin mais il voulut exalter par des louanges le mérite d'un si grand pontife et il s'efforça de répandre par une parole simple le bienfait qu'il savait avoir reçu par les mérites d'un si grand pontife. Ledit frère ne cessait d'évoquer avec admiration la nature et la gravité de l'infirmité dont il avait souffert.

\section{Leçon 11}

Il avait l'impression et certains autres aussi estimaient que cette infirmité appartenait au genre de mal qu'on appelle peste inguinale : c'est elle qui à l'époque du pape Grégoire [le Grand] avait affecté de manière très pernicieuse le peuple romain ${ }^{75}$. Ce qui arriva au peuple romain fut calmé de même par les sages conseils de ce très saint pontife. Et par quel ordre, par quelle raison ou sagesse les dommages qui étaient arrivés alors ont pris fin, ce n'est pas seulement le Siège apostolique qui le rappelle chaque année mais aussi l'Église universelle avec l'approbation du Christ ${ }^{76}$.

75. Pape de 590 à 604 . À son avènement, Rome souffrait d'une grande peste qui venait de faire mourir le pape Pélage II.

76. C'est par erreur sans doute que l'auteur se réfère ici à la messe du pape Grégoire où se produisit le célèbre miracle affirmant la présence réelle du sang dans le sacrifice eucharistique. 


\section{Leçon 12}

Le miracle que saint Grégoire opéra dans la multitude du peuple romain, le très saint Aubin l'a accompli en faveur d'un seul moine infirme et pèlerin. Il était logique que l'infirme guéri par saint Aubin montrât l'extrême gravité de son mal, afin que par la bonté, la "vertu " et la sainteté du guérisseur, ce guérisseur fût l'objet de louanges diffusées plus largement. Que la médecine spirituelle de saint Aubin soit pour toujours salutaire à tous ceux qui [le] servent pieusement. Au nom de Notre Seigneur Jésus-Christ qui est Dieu et Seigneur universel, qui vit et règne avec le Père et le Saint-Esprit pour les siècles des siècles. Amen.

\section{Miracles [écrits] par un moine d'Angers il y a plus de 600 ans $(B H L, 236)^{77}$}

\section{Prologue ${ }^{78}$}

Il faudrait demander à des hommes sages et cultivés les choses que vous, Pères et seigneurs très chers que l'habit et le culte de toute sainteté rendent vénérables, exigez avec beaucoup d'insistance de ma pauvre petite personne rustre et ignorante de toute espèce de philosophie : à savoir que mon zèle transmette par écrit les illustres miracles - ou [du moins] quelques-uns d'entre eux du très saint Aubin, confesseur et évêque - que le Seigneur a opérés par son intercession dans le temps présent. [Il dit que ce sont les miracles] que vous avez appris par le récit des fidèles et tous ceux que vous avez vous-même mérité de voir. [Arrêt du Prologue qui pour le reste est tout entier tissé de lieux communs $]^{79}$. Je rapporterai quelques miracles que j'ai connus par le récit d'hommes fidèles auxquels je dois faire confiance en raison de leur grand âge et de leur vie sainte, comme s'il m'avait été donné de les voir de mes propres yeux. Je les noterai de ma plume rustique, afin que s'il est permis un jour à quelqu'un [de les écrire] dans un style plein d'urbanité, il les orne d'un langage soigné sans provoquer mon envie.

\section{Possédés libérés au tombeau de saint Aubin; guérison d'une victime du feu ardent}

1. Dans le territoire d'Angers il y eut un homme appartenant à l'ordre équestre, nommé Bernier, qui soudain (nous ignorons par quel jugement

77. Le titre contenant la mention "il y a plus de 600 ans " a été ajouté au XVII ${ }^{\mathrm{e}}$ siècle. Éd. Acta sanctorum, Martis I, p. 60 sqq. d'après le manuscrit de Saint-Nicolas de Belfort et d'après le fonds de la reine Christine à la Bibliothèque vaticane, $\mathrm{n}^{\circ} 1025$, ms du $\mathrm{XI}^{\mathrm{e}}$ siècle, sans indication de provenance, ayant appartenu au XIII à l'abbaye de la Trinité de Vendôme, fol. 183-188, éd. partielle des passages inédits par dom BouQuET, Recueil des historiens de France, t. IX, p. 151-152 et PONCELET, Catalogus codicum hagiographicorum latinorum Bibliothecae Vaticanae [supra, n. 28], p. 403-404.

78. Fol. 183-184, éd. Poncelet, op. cit., p. 403.

79. Note de l'éditeur qui a résumé le texte. 
secret de Dieu) envahi par plus d'un démon, se mit à pousser des cris, à grincer des dents et à se déchirer lui-même. Ceux qui assistaient à cette crise de rage, frappés d'une grande terreur, se mirent à l'interroger sur ce qui venait de lui arriver. Mais lui se montra non seulement incapable d'entendre ou de rendre raison, mais encore il se précipita sur eux avec une grande violence, déchira les pauvres diables de ses morsures et de ses coups et les chassa tous de sa maison. Ses amis accablés de douleur, ignorant quel parti prendre pour lui (ils avaient l'impression qu'il y avait en lui non seulement la vigueur d'un homme mais les forces multiformes de l'Ennemi rugissant), firent venir des hommes vigoureux du voisinage, et, non sans grand péril, ils attachèrent cet homme en furie avec des cordes et des chaînes. Ensuite, s'efforçant de mettre en fuite le démon par de vaines incantations, pendant longtemps eux aussi tourmentèrent cet homme. Mais comprenant que cela non seulement ne servait à rien mais faisait aussi beaucoup de mal, prenant enfin un parti plus sage, ils décident de solliciter plutôt le secours de Dieu par le patronage de ses saints : ils se dirigèrent d'abord vers saint Julien, évêque du Mans († 348), portant tour à tour leur énergumène avec une certaine angoisse. Après avoir affronté diverses et grandes épreuves du voyage, fatigués, tristes et presque désespérés, sur le conseil de quelques personnes, ils arrivèrent au tombeau de saint Aubin. Comme ils avaient passé trois jours tendus dans la prière et le jeûne, le même troisième jour, cet homme tourmenté commença à s'endormir quelque peu, puis, son sommeil terminé, il fut complètement guéri. Alors consolant gentiment et raisonnablement les amis présents, il demanda à être délivré des chaînes qui l'enveloppaient. Ses amis étonnés, encore dans le doute et craignant que la bonté soudaine de cet homme ne soit qu'une illusion des démons, ne croyaient pas ses paroles jusqu'à ce que, au cours d'une longue conversation et du fait de ses réponses, ils reconnussent qu'il avait été guéri par la grâce du Christ.

2. Voici un autre miracle, qui n'est pas différent du précédent, qu'en ce temps-là Dieu daigna faire paraître par l'intermédiaire de son fidèle serviteur. Ameline en effet, jeune fille noble dans le siècle, sœur d'un certain Elinand, chevalier, demeurant aux confins de la Bretagne, au château de Craon $^{80}$, avait été longtemps tourmentée par un démon. Ses parents, ayant entendu parler de la renommée du saint évêque Aubin et de l'empire de sa puissance pour chasser les démons, conduisirent avec une grande confiance la possédée au monastère de ce saint; ils supplièrent instamment toute la sainte communauté des frères d'en appeler avec eux à leur saint patron, pour que celle que le Christ avait rachetée de son sang n'ait pas à souffrir d'être sous l'emprise du diable. Le pieux confesseur ne tarda pas à exaucer leurs prières et leurs vœux. Bientôt, en effet, l'esprit malin plein de superbe qui la torturait fut mis en fuite; la possédée retrouva une pleine santé, le Seigneur Christ triomphant par l'intercession de son humble serviteur.

80. Craon se trouve bien à la frontière entre la Bretagne et l'Anjou. 
3. À une autre époque aussi, dans un bourg appelé Cunault situé sur les bords de la Loire, un homme du nom de Berfroi souffrait d'un terrible mal : son pied était atteint du mal des ardents dont le feu l'avait déjà consumé jusqu'à la cheville. Aussi ne trouvant aucun remède dans la médecine, il crut que le seul remède qui pourrait lui être profitable serait de se rendre à la tombe du saint homme. Il y arrive donc et y demeure assez longtemps, ne cessant de supplier le saint d'éteindre par la rosée de son intervention le feu qui consumait son corps. Que dire de plus? Usant chaque jour le seuil de l'église, il ne cessa de prier qu'après que ce feu noir comme de la poix fut éteint dans son pied à demi brûlé.

La démonstration miraculeuse par [la guérison] au bout de sept années de la paralysie d'un homme pieux au sépulcre de saint Aubin

4. Il me semble qu'il faut introduire dans cet écrit ce qu'on sait avoir été accompli à notre époque au mausolée du saint pontife et ce que je sais avoir été connu par le récit de témoins oculaires. En effet, je ne me suis pas soucié de citer les noms de ceux dont les récits m'ont appris ces choses, parce que tous les citoyens d'Angers ont été témoins de ce fait, comme il apparaîtra clairement dans la relation de ce qui s'est passé. Dans le faubourg d'Angers donc, un fidèle du nom de Germond vivait avec sa femme : il ne possédait que peu de biens mais avait cependant de quoi satisfaire ses besoins et, ce qui est encore plus digne de louange dans le Christ, c'est qu'il était riche de bonté d'âme, de fermeté dans la vraie foi et de pure simplicité. Il lui vint un jour à l'esprit de se rendre, selon la coutume de toute la région, au saint sépulcre de saint Martin. Quand il y parvint, ce n'est pas la prospérité dans le siècle et une longue vie qu'il demanda mais l'indulgence pour ses négligences passées, le moyen d'échapper à celles qui étaient sur le point de se produire, la protection contre celles du futur, pour mériter de s'accomplir dans le Christ.

5. Le lendemain, alors qu'il prenait le chemin du retour chez lui, à la mi-journée, épuisé tant par la fatigue du corps que lassé par une lourdeur d'âme, s'éloignant un peu de la route, il se coucha sur le sol et s'endormit. Après son somme, son corps était si privé de forces qu'il ne pouvait plus avancer nulle part et que, difficilement, en se roulant longuement sur le sol, il put ramper jusqu'à la route avec beaucoup de peine. Il gisait sur le chemin, adressant des cris venus du fond du cœur à Dieu, secours dans les circonstances favorables [comme] dans les tribulations, tout en rendant grâce à la miséricorde divine avec [toute] la patience dont il était capable, puisqu'll daignait le visiter par son châtiment. Il avait en effet appris que Dieu châtie celui qu'il aime et qu'il flagelle tout fils qu'il reçoit ${ }^{81}$. Car le miséricordieux Créateur n'abandonne pas longtemps dans l'épreuve sans consolation celui qui continue longtemps à espérer en Lui sous le fouet. En effet, tandis que cet homme souffrant est dans le doute, ne sachant

81. He 12,6 . 
pas ce que la divine Providence a prévu pour lui, il aperçoit au loin des cavaliers venant sur la route où il gisait. Il s'agissait d'un citoyen d'Angers qui se rendait là où l'infirme voulait aller. Ce cavalier montra aussitôt de la compassion pour lui et il le fit hisser par ses gens sur un cheval (en vérité, il le connaissait bien) et le conduisit ainsi au château de Baugé; ensuite, un âne le porta jusqu'à sa maison où il demeura paralysé sur son lit une année entière.

6. L'année finie, ayant consumé ses pauvres biens, poussé par la nécessité plus que confiant dans sa santé, il fit l'effort de sortir de son lit. Certainement aidé par la grâce divine, il avait senti que sa main et son pied droits revenaient en se réchauffant à leur ancienne vigueur, le côté gauche de son corps restant aussi impotent qu'auparavant. Comme il demeurait pour l'instant sous le coup d'un tel châtiment, il chercha l'appui de béquilles : soutenu par celles-ci, il commença par visiter les églises et les monastères voisins de la cité : le plus souvent cependant, il fréquentait le seuil de Saint-Aubin non seulement pour y chercher la nourriture du corps qu'il recevait en aumône du monastère, mais aussi dans l'espoir d'obtenir le salut de son âme et de son corps par l'intervention du saint confesseur. Ensuite, avec le produit de la vente de quelque petit mobilier, il acheta un âne pour le transporter et lui permettre de visiter successivement le seuil des églises; enfin, avec sa fidèle épouse, il se rendit à Rome pour implorer l'aide des saints apôtres.

7. Sur le chemin du retour, une femme noble et pieuse l'accueillit dans la cité de Lucques; ayant reconnu la bonté de cet homme, elle le pria de rester avec elle, lui promettant que, tant qu'il vivrait, elle le servirait en toutes choses comme s'il était son propre père. Et lui, rendant grâce à Dieu de se souvenir de lui, accepta volontiers sur l'heure ce qu'elle lui proposait. Mais, au bout de quinze jours, de nouvelles suggestions le persuadant de retourner dans sa patrie, il commença à sentir en lui quelque trouble. D'abord, argumentant contre lui-même, il repoussait cette idée de son esprit : "Malheureux que je suis, disait-il, qui, dans ma patrie, me servira comme elle selon mes souhaits dans mon infirmité? Je ne partirai pas d'ici, j'attendrai ici la fin de mes jours. " Mais ensuite, dans son sommeil, il lui sembla apercevoir un homme d'une grande autorité qui, commençant par le flatter, lui disait : "Pars d'ici, pars et retourne à Angers; c'est en effet, là-bas beaucoup mieux qu'ici qu'on te procurera le salut du corps et de l'âme. " Ensuite, menaçant et effrayant, il ajouta que s'il ne lui obéissait pas, il arriverait quelque chose de pire. C'est pourquoi le lendemain, dans son épouvante, il demanda à la pieuse femme qui le servait non comme un indigent mais comme un maître, la permission de s'en aller (comme il me le racontait lui-même) et, au milieu des pleurs de la femme, il s'en alla lui-même dans la tristesse et retourna à Angers où tout le nécessaire lui fut fourni très volontiers par les fidèles; mais lui, poussé par quelque présage, refusant tous les autres gîtes, prenait plaisir à toujours séjourner dans le monastère de Saint-Aubin. Là, nuit et jour, il multipliait les prières 
au saint confesseur, lui demandant d'intervenir pour lui auprès du Juge miséricordieux.

8. Pendant que l'infirme se consacrait assidûment à ces prières, on en vient déjà à la septième année de son mal : arrive le jour anniversaire du susdit évêque. Aussi, la nuit des vigiles est-elle célébrée par des offices sacrés, à savoir des hymnes mélodieux, de pieux cantiques et des psaumes; au lever du jour, tous accourent : le clergé était présent avec le peuple de l'un et l'autre sexe ainsi qu'une foule non négligeable de nobles : le chœur des moines s'active, rassemblé au service de l'église. L'abbé Hubert d'heureuse mémoire, homme de grande simplicité et bonté se trouvait alors à la tête de la communauté de Saint-Aubin. étaient venus aussi plusieurs autres abbés accompagnés de leurs moines : aussitôt qu'ils eurent achevé les prières de la première heure, ils pénétrèrent dans le chapitre, comme il est prévu par les saints Pères ${ }^{82}$.

9. Pendant ce temps, Germond, bien qu'avec beaucoup de mal devant l'énorme foule des gens qui avaient rempli la basilique entière jusqu'à l'autel ${ }^{83}$, était entré dès le matin dans le sanctuaire (presbyterium); il s'était prosterné entre les deux autels, il implorait avec des gémissements et des larmes la clémence du pieux confesseur pour qu'il lui vienne en aide. Alors, comme lui-même le rapporte, il se sentit d'une dévotion et d'une componction de cœur plus ferventes et d'un amour plus débordant envers le saint : animé de cette ferveur, se vouant au service perpétuel du saint s'il guérissait, il abandonna la prière à laquelle il s'était longuement livré, se leva, se dirigea jusqu'aux portes devant l'autel dominical; les béquilles qui le soutenaient tombèrent d'un côté, comme si quelqu'un les avait arrachées, et lui-même tomba à demi-mort de l'autre côté, de façon que certains dans la foule dirent qu'il souffrait d'un malaise. Mais tous les autres disaient plus raisonnablement : "À la suite de ce signe, vous le verrez bientôt guéri par la puissance à l'œuvre du saint. » Et d'une seule voix ils criaient : « Secours-le, saint Aubin. " À peine cette voix eut-elle retenti que Germond commença à remuer le bras et sa main paralysée; son pied aussi, depuis si longtemps contracté et pendant, commença à s'allonger comme s'il était tiré par quelque grande force, si bien que certains des assistants rapportent qu'ils ont entendu pendant cette extension les craquements des nerfs de son genou; le sang qui en sortait également coula jusqu'au talon. Ainsi après sept ans d'infirmité, par l'œuvre du Christ, en raison des mérites du saint confesseur Aubin, sans aucune aide pour s'appuyer, il se dressa sur ses deux pieds, il s'avança devant tous d'une démarche assurée, rendant gloire au saint confesseur, auteur de sa guérison.

82. Il s'agit de la première heure du jour, de l'office de prime (Règle de saint Benoît, c. XVII). La référence aux Pères renvoie aux textes de Tertullien, Jérôme, Pélage qui " avaient légitimé la prière des heures " (voir VoGÜÉ Adalbert de, Règle de saint Benoît, t. VII, Paris, 1977, p. 340).

83. Il s'agit sans doute de l'autel du Crucifix où l'on célébrait la messe pour le peuple. 
10. Il y a dans le peuple une grande liesse, tous les cœurs sont remplis d'une joie spirituelle et naît en eux une componction nouvelle. Bientôt la louange et la jubilation montent vers le ciel [avec] le Te Deum laudamus, [chanté] d'une voix harmonieuse, auquel répond en même temps la sonnerie des cloches; le chapitre des moines s'interrompt : tous glorifient ensemble le nom de Dieu et rendent grâce au saint évêque Aubin, parce que tout libéré qu'il fût de la prison corruptible de cette vie, il n'abandonnait pas son peuple. Déjà le susdit abbé appelle Germond; apprenant de lui que tant que la vie ne le quitterait pas, il ne s'écarterait jamais du service du monastère, il lui ordonna de faire le service des pèlerins, des indigents et des infirmes, sous la direction du moine qui avait la charge des pauvres : " Allons, dit-il, prends la charge des infirmes et occupe-t-en, comme tu aurais voulu qu'on s'occupât de toi jusqu'à maintenant. Sois en paix avec ta conscience! Rends à ceux qui languissent la réciprocité du service que peu avant tu demandais aux fidèles qu'on te fît. " Germond reçut cette tâche avec une humble dévotion et c'est avec plus de dévotion encore qu'il l'exerça avec charité pendant sept ans. À la fin de sa vie, l'abbé et la communauté, après une longue pratique, reconnurent son humilité, sa charité et son obéissance, le reçurent dans la clôture du monastère ${ }^{84}$ et le revêtirent du saint habit. Mais bien que je n'aie que l'apparence du moine, j'ai vu ce moine s'appliquer avec la plus grande ferveur à la psalmodie et à la prière.

11. Et bien que j'aie entendu les choses que j'écris du seigneur Gautier, alors doyen du monastère et maintenant abbé ${ }^{85}$ (c'est lui qui m'a vivement incité à confier ce récit à la plume) et de nombreux autres qui furent présents à ce miracle, j'ai appris cependant avec plus de certitude tout cela de la bouche de Germond et les ai mises par écrit pour répondre à sa prière répétée et ses supplications. Ces prières, je les ai souvent repoussées (car je suis peu habile à cette activité) et je craignais qu'il ne fît cette demande que par un désir de vaine gloire. Je différais de me mettre au travail. "Qu'il te suffise, mon père, lui disais-je, d'avoir reçu dès cette vie une double faveur : tu as réussi à recouvrer la santé que tu avais perdue et tu as eu l'occasion de sauver ton âme par les prières du saint confesseur, bien qu'il soit plus glorieux d'espérer cela à la Résurrection, lorsque les justes recevront la gloire de l'immortalité dans leur corps comme dans leur âme. " Et lui disait au contraire : " La grâce de mon père très pieux m'a accordé plus de bonnes choses que je n'en pouvais espérer, alors que mes mérites anté-

84. Sans doute faut-il entendre par " clôture " non pas l'enclos du monastère, c'est-à-dire le vaste espace (exteriora) comprenant le jardin, le verger, les ateliers etc. où s'activaient les famuli - le famulus Germond s'y trouvait déjà - mais la clôture intérieure où vivaient les moines. Voir sur cette question les recherches récentes de CocHELIN, Isabelle, notamment "Les famuli à l'ombre des monastères (Cluny et Fleury, $\mathrm{X}^{\mathrm{e}}$ et $\mathrm{XI}^{\mathrm{e}}$ siècles) ", dans La vie quotidienne des moines en Orient et en Occident $\left(I^{e}-X^{e}\right)$, II : Questions transversales, DElouis, Olivier, et MossaKowSKA-GAUBERT, Maria, éd., Institut français d'archéologie orientale du Caire (IFAO) et École française d'Athènes, à paraître.

85. 1036-1043. 
rieurs ne valaient rien. Mais il y a quelque chose dont je me réjouis pour la gloire du Christ, et non pas pour moi, c'est que tous ces gens qui ont connu ma faiblesse jusqu'à ce qu'ils me voient guéri par l'intervention de notre patron, glorifient le nom du Christ, de son confesseur, à savoir saint Aubin, qu'ils magnifient et propagent sa 'vertu'. " C'est pourquoi je désire avec la plus grande force que ce qui s'est produit maintenant par la vue pour l'édification des âmes, soit mis par écrit pour la lecture et l'écoute ${ }^{86}$ jusqu'à la fin des siècles, [à savoir] ce que notre patron saint Aubin a accompli dans ma personne pour la louange et la gloire de Notre Seigneur Jésus-Christ.

\section{Victoire sur les ennemis de saint Aubin, l'habitude de jurer châtiée.}

12. Le lieu de naissance du saint évêque n'est pas privé de la munificence de ses vertus. En effet, dans le pays de Vannes, il existe une bourgade située au bord de l'Océan que la langue bretonne appelle Guérande, assez peuplée en raison d'un important commerce du sel. Les habitants de ce lieu vénèrent le saint confesseur avec un saint amour et, après le Christ, c'est à lui qu'ils rendent un culte avec une remarquable vénération, ce qu'atteste la magnifique basilique construite en son honneur par le zèle des Guérandais. Dans le port de cette bourgade arriva un jour une grande flotte de navires de guerre transportant des pirates nordiques que nous avons l'habitude d'appeler Normands : c'est une race sauvage et très cruelle d'hommes assoiffés de faire couler le sang humain, de convoiter avidement les biens d'autrui, de capturer les jeunes gens et les jeunes filles, de tuer les vieillards sans aucune pitié. C'est pourquoi leur arrivée imprévue terrorisa si fort tous les habitants de cette terre qu'ils ne surent pas du tout ce qu'ils devaient faire et vers où se tourner. Pas de forces pour résister, pas de possibilité de fuir si ce n'est en abandonnant les enfants, les femmes et tous leurs biens meubles. Se rassemblant cependant eux-mêmes au son des trompettes, tous se réfugient dans l'église Saint-Aubin, en faisant de nombreux vœux : ils réclament en pleurant qu'Aubin les aide, qu'il soit leur avoué, leur chef et leur porte-étendard.

13. Au milieu d'une agitation désordonnée, un homme noble (curialis) que son aspect remarquable rendait digne de respect [mais] que personne ne connaissait, apparut avec l'habit d'un chevalier, revêtu d'armes étincelantes. Leur reprochant leur lenteur, il leur dit : "Ô espèces d'engourdis, hommes de peu de foi, pourquoi hésitez-vous à aller combattre un peuple qui vit sans Dieu? Est-il impossible à notre Seigneur le Christ de triompher d'un grand ou d'un petit nombre d'adversaires? Alors surtout que saint Aubin priant depuis longtemps nous attend, prêt à vous offrir son aide? Rappelez-vous que David, l'enfant désarmé, a étendu sur le sol d'une seule pierre le géant Goliath qui faisait peur à tout le monde. " L'esprit enflammé par ces paroles, tous se lancent au combat contre les ennemis déjà là,

86. Il est intéressant de relever que l'hagiographe distingue la lecture muette et la lecture à haute voix. 
prêts à tout envahir, à tout arracher, ne doutant pas de tuer et de brûler. La petite troupe de saint Aubin se lance à l'assaut contre l'ennemi : bien qu'il soit supérieur en nombre et qu'eux soient désarmés en face d'adversaires armés, sans expérience du combat contre des ennemis exercés, forts non de leurs forces mais de celles de Dieu, ils écrasèrent les rangs des ennemis. Les pirates sentant que c'était Dieu qui combattait contre eux et non des hommes, s'enfuirent plus rapidement qu'ils n'étaient venus, rejoignant leurs navires et n'osant plus ensuite envahir ces terres.

14. Les ennemis ayant été vaincus et mis en fuite avec l'aide du saint, les Guérandais enquêtent et ils constatent que dans un si grand affrontement aucun des leurs n'avait péri mais même qu'aucun n'avait été blessé : ils se rendent compte que seul ce guerrier inconnu, qui était venu en renfort, manque à l'appel. À cette nouvelle, rendus très affligés et très tristes de ce qui était arrivé (ils supposaient en effet que celui qui s'était élancé en avant contre les rangs des ennemis avait été tué), ils scrutent avec soin les cadavres afin de lui donner les honneurs d'une sépulture. Mais ils ne le trouvent pas, et déjà plus personne ne doutait qu'il s'agissait d'une force ou puissance (virtus) angélique, envoyée par le Seigneur pour aider un peuple qui s'était voué [à lui]. Cela ayant été accompli ainsi avec bonheur, ils se rendent tous dans la basilique du saint confesseur faisant des vœux tout en sacrifiant à la louange.

15. Au temps où le vénérable abbé Otbran dirigeait l'abbaye de saint Aubin, évêque d'Angers, Dieu manifestant sa compassion pour les misères des hommes, prouvant qu'il condamnait la propension irréfléchie à jurer et l'horreur des jurons, par l'épreuve d'un seul terrifia les uns et par le soulagement qui lui fut accordé en retour, réconforta tous les autres. Le jour qui est dédié à Mercure par les Anciens qui étaient dans l'erreur, un adolescent appelé Foulque, fils d'un chevalier nommé Thierry, du château de Chemillé ${ }^{87}$, avait atteint Thouars ${ }^{88}$ - ce nom est celui d'une bourgade voisine - avec d'autres hommes et des bêtes de somme lourdement chargées pour exécuter un ordre de son père. Tandis que les bêtes étaient sur le retour après avoir été chargées de blé - transport pour lequel elles étaient venues -, voici ce qui arriva audit Foulque : en voulant relever le bât déséquilibré d'un âne, il se fit très mal à la blessure qui lui avait été cruellement infligée récemment à la main. Aussi était-il en colère contre celui qui l'avait blessé, bien qu'il fût absent : il voulait souhaiter à cet homme qu'il fût à son tour atteint du même mal et exprimer le mouvement de son âme en jurant par [le nom] du précieux Aubin. Après qu'il eut invoqué sans précaution le nom du saint, avant même qu'il n'eût exprimé par des paroles les mouvements passionnés de son âme, il devint subitement muet. Comme ses compagnons s'enquéraient de la raison de ce silence et qu'ils ne pouvaient tirer de lui que des larmes et quelques hochements de tête, ils le ramenèrent à son père.

87. Chemillé-Melay, ch.-l. c., ar. Cholet, Maine-et-Loire.

88. Thouars, ch.-l. c, ar. Bressuire, Deux-Sèvres. 
16. Peu de temps après, la renommée d'un tel événement se répandit dans tout le voisinage et les parents entreprirent de tenir conseil : il fallait chercher le soulagement de l'enfant en recourant aux suffrages de celui par qui il avait perdu la parole en l'offensant. Le père donc, ayant réuni ses amis, envoya son fils à Angers et il le recommanda aux prières des moines soumis à saint Aubin. Après l'avoir accueilli, ceux-ci offrirent leurs prières à Dieu et à saint Aubin, imposant à l'enfant prosterné devant le très saint corps une très pieuse persévérance; le laissant en ce lieu seul, ils se retirèrent après avoir fermé sur lui les portes du lieu saint (sacrarium) (car c'était déjà le soir). Comme ce dernier se répandait en larmes et gémissements plutôt qu'en voix et paroles, il s'endormit subitement. Saint Aubin se présenta devant lui sans tarder, le visage doux et en habit blanc : lui adressant d'abord des paroles de miséricorde, il lui ordonna de se lever et de parler. Ensuite il lui exposa la cause de ce qui lui était arrivé, qu'à vrai dire, ce n'était pas pour ses péchés seulement mais pour les péchés de tous ceux qui avaient eu l'audace de jurer en invoquant le nom de Dieu et des saints de manière irrévérencieuse et pour prouver leur audace. Ensuite il lui prescrivit de corriger sa vie, d'avoir du respect pour Dieu et pour ses saints ainsi que d'avertir tous ceux qu'il pourrait d'éviter avec soin les choses illicites, d'instruire aussi les serviteurs de cette église pour que dans ce lieu que Dieu aimait ils servissent de façon à mériter le rang promis aux bons serviteurs, de passer lui-même toute sa vie en ce lieu au service de Dieu et à son service. Après avoir prononcé ces paroles, il se retire et, comme l'adolescent nous l'a raconté par la suite, il s'éleva en sortant par la vitre placée devant le mausolée. Le muet crie immédiatement : "Saint Aubin, pourquoi es-tu parti? " Les moines arrivent en même temps qu'ils entendent les cris du muet qui parle. Après que ce muet qui reparle nous eut fait le récit - en effet, moi, quoiqu'indigne, j'ai assisté à ce miracle admirable -, comprenant la miséricorde de Dieu qui nous avait dressés par l'exemple d'un seul à la prudence contre le mal, nous avons glorifié par la douceur des hymnes ces «merveilles ". Dieu qui vit et règne pour les siècles des siècles. Amen.

\section{Vie métrique de saint Aubin ${ }^{89}$}

a. Le saint amène le roi à renoncer à une chasse $\mathrm{e}^{90}$

1. Il allait à Paris dans la capitale de ce prince

2. Le vénérable Aubin en [chantant] des hymnes convenables.

3. Il s'y rendait lentement déjà entravé par le grand âge.

4. Alors que, fatigué, il se repose près des murs d'une ferme,

5. Le roi, [entouré] d'une troupe de jeunes chasseurs et de ses grands,

6 . Voulait sortir de la ville le lendemain

7. Pour chasser et parcourir les forêts.

89. Bibliothèque municipale d'Angers, 299 (290), f. Aiv col. a; éd. DolBEAU, « Pierre, moine de Saint-Serge " [supra, n. 39], p. 821-822.

90. Chapitre 14 de la Vita s. Albini. 
8. Le susdit saint lui fait parvenir ce message :

9. Je n'avance que lentement, roi ami de la paix,

10. Aussi, je t'en prie, arrête-toi afin qu'il ne t'arrive rien de fâcheux.

11. Ne méprise pas l'ordre que je te donne de t'arrêter.

12. L'ordre d'un roi vaut moins que celui d'un pontife.

13. Le roi est sacré par l'évêque, l'évêque est assisté par le roi.

14. Le roi entendit ces paroles et obéit volontiers au saint.

15. Non seulement il s'arrêta mais il voulut se hâter de le rejoindre.

16. Il monta sur son puissant cheval et partit accompagné de ses troupes.

17. Il laissa la chasse et se hâta à la rencontre du saint.

18. Aubin obtient de Dieu ce qu'un juge lui avait refusé ${ }^{91}$.

19. Changeant de route, ce saint gagne la demeure du juge.

20. Il prie pour les accusés mais c'est en vain qu'il s'échine à parler.

21. Il presse et supplie, mais tout ce qu'il demande est refusé.

22. Les souhaits du vieil homme ne donnent rien, c'est prêcher dans le désert ${ }^{92}$

22. Car l'homme mauvais se rengorge quand on le supplie.

23. La sentence d'un cœur cruel ne sait pas s'adoucir.

24. Mais c'est aux cieux que le fidèle demande les soulagements connus.

25. Prostré tout près de leur lieu de torture,

26. l'homme pieux pleure pour les condamnés.

27. Né pour soigner ceux qui languissent

28. et pour réchauffer ceux qui souffrent,

29. il prie et le vœu de l'orant est accompli par la loi de celui qui tonne.

30. Il [le tonnerre] brise une grosse pierre de la prison

31. offrant aux enchaînés une sortie et leur ouvrant le moyen de s'échapper.

32. La troupe se soustrait aux peines en brisant ses chaînes,

34. rendant grâce à Aubin pour ce beau présent.

\section{Translation des reliques de saint Aubin d'Angers en 1128 (BHL, 237) ${ }^{93}$}

L'an de l'incarnation du Seigneur 1128, indiction VI, Louis [VI], fils de Philippe [ $\left.{ }^{\mathrm{er}}\right]$, gouvernant avec force (strenue) le royaume de France, Girard, évêque d'Angoulême, légat du Siège romain ${ }^{94}$, et Hildebert [de Lavardin],

91. Chapitre 17 de la Vita s. Albini.

92. Littéralement : c'est la graine qui parle au sable.

93. Dom MORICE, Mémoires pour servir de preuves à l'histoire ecclésiastique et civile de Bretagne..., t. I, Paris, 1742, col. 559, d'après un " ancien calendrier de S. Aubin d'Angers " et Annales de Saint-Aubin, dans Recueil d'annales angevines ou vendômoises, éd. HALPHEN [supra, n. 8], qui date la translation des calendes de mars ( $1^{\mathrm{er}}$ mars) MXXVIII. Translatio sancti Albini, kalendis martis in novam capsam (op. cit., p. 8, voir annexe 2), c'est-à-dire le jour même de la depositio sancti Albini.

94. Girard, évêque d'Angoulême, légat du Siège romain (1102-1136). 
archevêque de Tours ${ }^{95}$, avec les vénérables évêques Guy [de Ploermel] du Mans ${ }^{96}$, Hamelin de Rennes ${ }^{97}$, Ulger d'Angers ${ }^{98}$. Brice de Nantes ${ }^{99}$ se réunirent [à Angers] ${ }^{100}$ pour la translation du corps de saint Aubin évêque, dans une nouvelle châsse merveilleusement ornée d'or et d'argent, en présence du seigneur Foulque ${ }^{101}$, très noble consul.

\begin{abstract}
RÉSUMÉ
Le culte de saint Aubin a commencé très tôt puisque Grégoire de Tours rapporte deux de ses miracles. Déposé depuis le vie siècle dans une basilique suburbaine qui a pris le nom de saint Aubin, le corps du saint évêque reposait au $\mathrm{XI}^{\mathrm{e}}$ siècle dans la crypte de l'abbatiale du puissant monastère angevin. C'est là qu'eurent lieu la plupart des miracles. Ils sont rassemblés dans deux groupes de récits, écrits l'un et l'autre au $\mathrm{XI}^{\mathrm{e}}$ siècle. Il s'agit surtout de récits de guérison, mais ils nous renseignent aussi sur divers aspects de la vie quotidienne. Composés par des moines de saint Aubin, ces miracles du $\mathrm{XI}^{\mathrm{e}}$ siècle témoignent à la fois de l'activité du scriptorium de l'abbaye et de la ferveur qui entourait la tradition hagiographique du saint fondateur.
\end{abstract}

\title{
ABSTACT
}

The cult of St Aubin is attested very early on since Gregory of Tours related two of his miracles. He was originally buried in a suburban basilica dedicated to the saint: in the 11th century his body was in the crypt of the abbey Saint-Aubin, one of the most powerful monasteries of Anjou. Most of miracles were operated here. Written in the 11th century, they form two collections of narratives. They mostly concern the healing of sickness, but they also give details of some aspects of everyday life. Composed by the monks of Saint-Aubin, the miracles bear witness to the activity of their scriptorium and of the enthusiast fervour which vivified the hagiographic tradition of saint Aubin.

95. Hildebert de Lavardin, écolâtre puis évêque du Mans (1096), archevêque de Tours de 1125 à 1133 (Moos, Peter von, Dictionnaire de Spiritualité, t. VII, p. 502-504 et Foulon, Église et réforme au Moyen Âge [supra, n. 9], p. 151 ss).

96. Guy de Ploërmel, successeur d'Hildebert de Lavardin au Mans de 1125 à 1135.

97. Évêque de Rennes de 1127 à 1141.

98. Sur Ulger, magister scolarum puis évêque d'Angers de 1125 à 1149 (voir Foulon, Ibid., p. 150-151, 324 et passim).

99. Évêque de Nantes de 1112 à 1140 .

100. Comme le remarque Jean-Hervé Foulon (Ibid., p. 501) : "À travers de telles célébrations, étaient manifestées ostensiblement la supériorité de l'ordre sacerdotal sur le monde et sa nécessaire médiation dans le domaine du salut. "

101. Il s'agit de Foulque V le Jeune, comte d'Anjou de 1108 à 1129. 